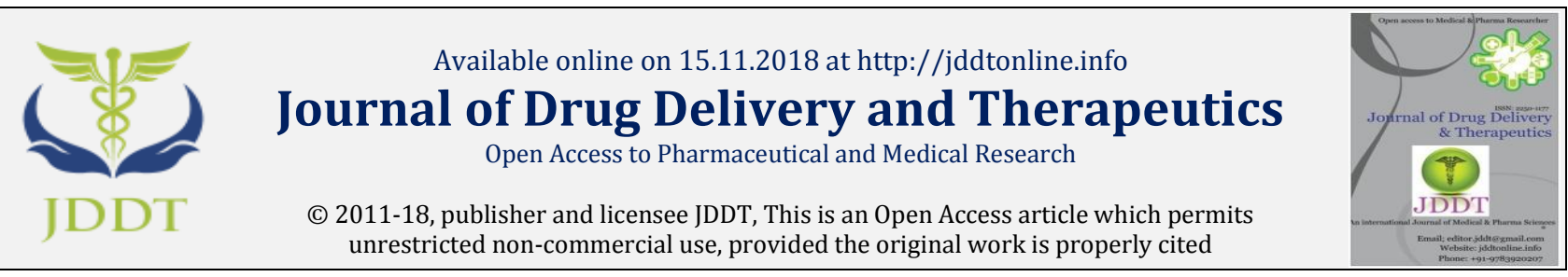

Open $\odot$ Access

Review Article

\title{
Oral dissolving film: present and future aspects
}

\author{
Kaur Prabhjot* and Garg Rajeev
}

Department of Pharmaceutics, Amar Shaheed Baba Ajit Singh Jujhar Singh Memorial College of pharmacy, Bela (Ropar), Punjab, India

\begin{abstract}
Over the past few decades, tendency toward innovative drug delivery systems has almightily increased attempts to ensure efficacy, safety and patient acceptability. As discovery and development of new chemical agents is a complex, expensive and time consuming process, so recent trends are shifting toward designing and developing innovative drug delivery systems for existing drugs. Orally fast dissolving film is the kind of drug delivery system which when placed in the oral cavity, disintegrate or dissolve within a few seconds without the intake of water. Oral fast dissolving film is relatively new dosage form in which thin film is prepared using hydrophilic polymers, which rapidly disintegrate or dissolves on tongue or in the buccal cavity It is an alternative platform for molecules that undergoes high first pass metabolism. The method of preparation for oral dissolving film. Solvent casting, Semisolid casting, Hot melt extrusion, Solid dispersion extrusion, Rolling The current evaluation gives an account of different formulations methods of preparation and quality control of the fast dissolving oral thin film.
\end{abstract}

Keyword: First pass metabolism, Tensile strength, Fast Dissolving Oral Film etc.

Article Info: Received 03 Oct, 2018; Review Completed 09 Nov 2018; Accepted 12 Nov 2018; Available online 15 Nov 2018

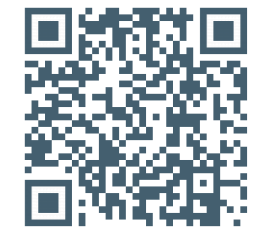

\section{Cite this article as:}

Kaur P, Garg R, Oral dissolving film: present and future aspects, Journal of Drug Delivery and Therapeutics. 2018; 8(6):373-377 DOI: http://dx.doi.org/10.22270/jddt.v8i6.2050

\section{*Address for Correspondence:}

Prabhjot Kaur, Department of Pharmaceutics, Amar Shaheed Baba Ajit Singh Jujhar Singh Memorial College of pharmacy, Bela (Ropar), Punjab, India

\section{INTRODUCTION}

Orally fast-dissolving film is new drug delivery system for the oral delivery of the drugs. Almost $90 \%$ of the drugs are administered to the body via oral route for the treatment of various disorders and diseases as it is regarded as the safest, most convenient and most economical method of drug delivery and have the highest patient compliance. ${ }^{1-4}$. The drug is either dissolved or swallowed, which then enters into the systemic circulation to produce the desired effect ${ }^{5-6}$. Fast dissolving oral thin films is an ultra thin film that employs a hydrophilic polymer that rapidly hydrates or adheres when placed on the tongue or in the buccal cavity ${ }^{7}$. These films disintegrate or dissolve within seconds to release the active agent without drinking and chewing 8,9 . The instant bioavailability results from bypassing first pass metabolism. So they are generally designed for the drugs having high first pass metabolism for achieving better bioavailability 10,11 .

\section{Advantages ${ }^{12,13}$}

1. Easy transportation

2. No need of water for administration

3. Oral strip technology provides an alternate route for drugs with first pass metabolism ${ }^{14}$.
4. Ease of administration of film to the patients suffering from dysphagia, repeated emesis, motion sickness, and mental disorders

5. Large surface area provides rapid disintegration and dissolution in the oral cavity.

\section{Disadvantages 15}

1. Drugs which are unstable at buccal $\mathrm{pH}$ cannot be administered.

2. Drugs with high dose cannot be incorporated into the film

3. Drugs which irritate the mucosa cannot be administered by this route

4. As it is fragile and must be protected from water, it requires special packaging.

\section{FORMULATION CONSIDERATION}

$>$ Active pharmaceutical ingredient

$>$ Film forming polymers

$>$ Plasticizer

$>$ Sweetening agent

$>$ Saliva stimulating agent

$>$ Flavoring agent

$>$ Coloring agent 


\section{Active pharmaceutical ingredient}

A typical formation of the film contains $1-25 \% \mathrm{w} / \mathrm{w}$ of the drug. Variety of active pharmaceutical ingredients can be delivered through fast dissolving films. Small dose molecules are the best candidates to be incorporated in oral fast dissolving films. Multivitamins up to $10 \% \mathrm{w} / \mathrm{w}$ of dry film weight was absorb in the films with dissolution time of less than 60 seconds. It is always useful to have micronized active pharmaceutical ingredients which will improve the texture of the film and also for better dissolution and uniformity in the oral fast dissolving films. Many active pharmaceutical ingredients, which are potential candidates for oral fast dissolving films technology, have bitter taste. This makes the formulation uneatable especially for pediatric preparations. Thus before incorporating the active pharmaceutical ingredients in the oral fast dissolving films, the taste needs to be masked. Various methods can be used to improve the edible of the formulation. Among the techniques employed, the simplest method involves the mixing and co-processing of bitter tasting active pharmaceutical ingredients with excipients with pleasurable taste. This is often termed as obscuration technique. 16-21.

\section{Film-Forming Polymers}

Polymers are the most important ingredient of the fast dissolving oral film. Robustness of the film depends on the quantity of polymer added in the oral strip. Generally, $45 \%$ $\mathrm{w} / \mathrm{w}$ of polymer is used which is based on total weight of dry film. The selection of polymer is one of the most important and critical parameters for the successful development of oral films because of their tensile strength which depends upon the type and quantity of polymer used 22. Mainly hydrophilic polymers are used in the oral strip as they rapidly disintegrate in the

oral cavity as they come in contact with saliva ${ }^{23}$. Currently, both natural \& synthetic polymers are used for the preparation of fast dissolving film.

\section{Plasticizers 24-28}

It is an main ingredient of oral thin films. The plasticizers help to better the mechanical properties of film such as tensile strength and elongation to the film. It also minimizes the brittleness of the film. It may better the flow and enhances the strength of polymer. The proper selection of the plasticizers is very main. It should be compatible with the drug, polymers as well as with the other excipients. The irrerular selection may cause cracking, splitting and peeling of the film. The commonly used plasticizers are glycerol, propylene glycol, polyethylene glycol, dimethyl, dibutyl, diethyl phthalate, ntributyl, triethyl, actyl citrate, triacetin and castor oil.

\section{Surfactants 29-30}

Surfactants are used as a wetting or solubilizing or dispersing agent so that the film is getting dissolved within seconds and release active agent immediately. Commonly employed are poloxamer 407, benzethonium chloride, sodium lauryl sulfate, tweens, benzalkonium chloride, etc. Out of these most predominantly used surfactants is poloxamer 407.

\section{Sweetening agents ${ }^{31-32}$}

Sucrose is the most commonly used sweeteners in fast dissolving oral films. Sucrose is very soluble in water and being colorless does not impart any undesirable color to the final formulation. Some of the commonly employed sweeteners are dextrose, sucrose, fructose, glucose, isomaltose, polyhydric alcohols (sorbitol, mannitol), etc. Artificial sweeteners like saccharin, cyclamate, aspartame (first generation), sucralose, alitame and neotame (second generation) can also be used.

\section{Saliva stimulating agents ${ }^{33}$}

Saliva stimulating agents are used to increase the rate of making of saliva that would help in the faster disintegration of the quick dissolving strip formulations. Examples of salivary stimulants are citric acid, malic acid, lactic acid, ascorbic acid and tartaric acid.

\section{Flavouring agents ${ }^{31}$}

Flavours used in the formulation must be non-toxic, soluble, stable and compatible with the excipients. The quantity of flavouring agent required to mask the taste depends on the flavor type and its strength.

\section{Colouring agents 34}

Generally incorporated colouring agents have FD\&C approved colours, natural colours, pigments such as titanium dioxide etc. The colouring agents should not exceed concentration levels of $1 \% \mathrm{w} / \mathrm{w}$.

\section{METHOD OF PREPARATION 35-37}

There are five methods which are used alone or in a combination with the following process for the manufacture of the fast dissolving oral films

i) Solvent casting

ii) Semisolid casting

iii) Hot melt extrusion

iv) Solid dispersion extrusion

v) Rolling

\section{Solvent casting ${ }^{38-39}$}

Water soluble polymers and plasticizers are dissolved in a acceptable volatile solvent like Ethanol or distilled water to form a clear viscous solution. Solution is stirred for $2 \mathrm{hrs}$ in the magnetic stirrer and kept aside active pharmaceutical ingredient and other ingredients are dissolved in aqueous solvent and are combined with the bulk. The entrapped air is separate by vacuum Finally the solution is casted into a acceptable Petri dish and dried in an oven at 50 oC for 24 hrs Film is cut into desired size and shape.

\section{Semisolid casting ${ }^{38-39}$}

Solution of water soluble film forming polymer is prepared It is poured into the solution of acid insoluble polymers in the ratio of 1:4 A gel mass is obtained by the incorporation of relevant quantity of plasticizer it is casted into the films or ribbons by using heat controlled drums. The diameter of the film should be about $0.015-0.05$ inches.

\section{Hot melt extrusion 4041}

In hot melt extrusion method essentially the drug is mixed with carrier in solid form. Then dried granular material is introduced into the extruder. The short speed should set at $15 \mathrm{rpm}$ in order to process the granules inside the barrel of the extruder for approximately $3-4 \mathrm{~min}$. The processing temperatures should be $800 \mathrm{C}$ (zone 1), 1150C (zone 2), 1000C (zone 3) and 650C (zone 4). The extrudate ( $\mathrm{T}=$ 650C) then depressed into a cylindrical calendar in order to obtain a film. There are certain comforts of hot melt extrusion 28,29 . 
-Fewer operation units

-Better content uniformity

-An anhydrous process

\section{Solid dispersion extrusion ${ }^{39-41}$}

In this method, the presence of amorphous hydrophilic polymers, one or more active ingredients are dispersed in an suspended carrier in a solid state. Active Pharmaceutical Ingredient is dissolved in a suitable solvent to obtain a solution Solution is added into the melt of suitable polymer (PEG) below $70{ }^{\circ} \mathrm{C}$ without removing liquid solvent Finally by a means of dies, solid dispersion are form into films.

\section{Rolling ${ }^{42-43}$}

Firstly a pre-mix is prepared by film forming polymers, polar solvent and other add on except a drug. Add required quantity of drug to the pre-mix. The drug is blended with pre-mix to obtain stable matrix. The mixture obtained is fed into the roller. Film is formed and carried off by support roller. Wet film is then dried utilized controlled bottom drying. Film is cut into desired size and shape.

\section{EVALUATION PARAMETERS $\mathbf{4 4 - 4 5}$}

1. Mechanical Properties-

- Thickness test- Thickness specifies the dose perfection of drug in the film. It is measured by a micrometer screw gauge or calibrated digital Vernier calipers at five unlike strategic locations and the mean value is calculated which indicates the final thickness of the film. The width of the film should be in the range of $5-200 \mu \mathrm{m}$.

- Dryness test- About eight stages of the film drying process have been identified and they are set-to-touch, dust-free, tack-free (surface dry), Dry-to touch, dry-hard, dry-through (dry-to-handle), dry-to-recoat and dry print-free. Although these tests are essentially used for paint films most of the studies can be change intricately to evaluate pharmaceutical OFDF. The details of estimation of these parameters can be checked elsewhere and are beyond the scope of this review. Tack is the determination with which the strip adheres to an accessory (a piece of paper) that has been pressed into contact with the strip. Instruments are also available for this study.

- Tensile strength- Tensile strength is the highest stress applied to a point at which the strip specimen breaks. It is calculated by the applied load at break divided by the cross sectional area of the strip as Given in the equation below:

Tensile Strength $=$

load of breakage/ strip thickness $\times$ strip width

- Percent elongation- When stress is appeal, a strip sample stretches and this is mention to as strain. Strain is basically the deformation of strip split by original dimension of the sample.

Generally elongation of strip increases as the plasticizer content increases30.

$\%$ Elongation $=$ Increase in length $\times 100 /$ original length

- Young's modulus- It is the estimate of film stiffness. It is found as balance of applied stress to the strain in the elastic deformation region. It is determined by the following formula:
Young's modulus =

(Slope/strip thickness * cross head speed)/ 100

It can also be written as:

Young's modulus $=$ force at corresponding strain/ crosssectional area*corresponding strain

Hardness and brittleness are attributing of the films which are related with Young's modulus and tensile strength. A hard and brittle film represents higher value of tensile strength and Young's modulus with small elongation.

- Tear resistance- Tear resistance of plastic film is a complex function of its ideal resistance to rupture. Basically very short rate of loading $51 \mathrm{~mm} \mathrm{(2} \mathrm{in)/min}$ is employed and is designed to measure the force to begin tearing. The maximum force required to tear the specimen is recorded as the tear resistance value in Newton.

- Folding endurance- Folding endurance is set by repeated folding of the strip at the same place till the strip breaks. The number of times the film is folded without breaking is evaluating as the folding endurance value.

\section{Transparency ${ }^{46-47}$}

The transparency of the films can be decide using a simple UV spectrophotometer. Cut the film samples into rectangles and placed on the inner side of the spectrophotometer cell. The direct transmittance of films at $600 \mathrm{~nm}$. The transparency of the films was calculated as follows:

$$
\text { Transparency }=(\log \mathrm{T} 600) / \mathrm{b}=-€ \mathrm{c}
$$

Where T600 is the transmittance at $600 \mathrm{~nm}$ and $\mathrm{b}$ is the film thickness $(\mathrm{mm})$ and $\mathrm{c}$ is concentration.

\section{Contact angle $44-45$}

It allows the information about wetting behavior, disintegration time and dissolution of oral film. This can be executing with the help of goniometer at room temperature. For this cause, double distilled water should be used. A dry film is taken and a drop of double distilled water is situating on surface of the dry film. Images of water droplet are taken by a convey of digital camera within $10 \mathrm{~s}$ of deposition. Digital pictures should be analysed by image $\mathrm{J} 1.28 \mathrm{v}$ software for angle determination.

\section{Scanning electron microscopy ${ }^{4-48}$}

Scanning electron microscopy is an prime method to study the surface morphology of the film between different excipients and drug. A film sample is taken and placed in sample holder and at $\times 1000$ magnification and various photomicrographs were taken using the tungsten filament as source of electron.

\section{In vitro disintegration test ${ }^{47-48}$}

It is the time at which the film disintegrates when conduct in contact with water. This test is carried out by position the film in the phosphate buffer. United State Pharmacopoeia disintegration apparatus can be also used to study the disintegration time. The disintegration time should be in the range of $5-30 \mathrm{sec}$.

\section{In-vitro dissolution test ${ }^{47-48}$}

Amount of drug substance that proceeds into the solution per unit time under standard conditions of temp, solvent concentration and liquid/solid interface is called 
dissolution. A standard paddle apparatus described in any of the pharmacopoeia can be used for dissolution testing. When paddle type dissolution apparatus is used, it's difficult to perform dissolution study of oral film as they can float above the dissolution medium. Selection of the dissolution media depends on the sink conditions and the highest dose of drug. During dissolution study, the temperature of the medium should be maintained at $37 \pm$ $0.5 \mathrm{oC}$ and rpm at 50 .

\section{Stability studies ${ }^{49-51}$}

Stability testing of the prepared formulation is mainly ready to check whether it is a stable product or not. It is also used for the determination of effect of temperature and humidity on the stability of the drug for the actual storage, initially the formulation is wrapped in a butter paper followed by aluminum foil wrapping over it, then this is load in an aluminum pouch and heat sealed. Formulation should be stored at 45oC / $75 \%$ RH for 3 months. Through the time of stability studies, triplicate samples are taken at three sampling intervals i.e. 0,1 and 3 month and films should be evaluated for physical changes and drug content.

Table 1: Comparison between Fast Dissolving Oral Films and Fast Dissolving Tablets

\begin{tabular}{|l|l|l|}
\hline Sr No. & Fast Dissolving Oral Film & Fast Dissolving Tablet \\
\hline 1 & It is a film & It is a tablet \\
\hline 2 & Greater dissolution due to larger surface area & Lesser dissolution due to less surface area \\
\hline 3 & Low dose can only be incorporated & High dose can be incorporated \\
\hline 4 & More patient compliance & Less patient compliance than films \\
\hline 5 & No risk of chocking & It has a fear of chocking \\
\hline
\end{tabular}

\section{CONCLUSION}

Fast dissolving oral films have better patient compliance and may improve biopharmaceutical properties, improve efficacy and better safety, compared with conventional oral dosage forms. After the Fast Dissolving Tablets, the new products as Fast Dissolving Oral Fasts are intended for the application in the oral cavity and they are innovative and promising dosage form especially for use in elder patients. The development of fast dissolving drug products also

\section{REFERENCES}

1. Hema Chaudhary, Samita Gauri, Permender Rathee, Vikash Kumar Development and optimization of fast dissolving orodispersible films of granisetron $\mathrm{HCl}$ using Box-Behnken statistical design Bulletin of Faculty of Pharmacy, Cairo University Cairo University (2013)51:193-201

2. . Bhowmik D, Chiranjib B, Krishnakanth, Pankaj, Chandra RM, Fast dissolving tablet: an overview. J Chem Pharm Res 2009; 1:163-77

3. Flash release oral films of metoclopramide hydrochloride for pediatric use: formulation and in-vitro evaluation. Raju S, Reddy PS, Kumar VA, Deepthi A, Reddy KS, Reddy PVM. J Chem Pharm Res 2011; 3(4):636-46.

4. Routes of drug administration. Verma P, Thakur AS, Deshmukh K, Jha AK, Verma S. Int J Pharm StudiesRes 2010; 1(1):54-9.

5. Formulation of a novel Tianeptine sodium orodispersible film. Setouhy DA, Malak NS. AAPS Pharm Sci Tech 2010; 11(3):101825.

6. Fast disintegrating tablets: an overview of formulation, technology, and evaluation Puttalingaiah L, Kunchu K, Tamizh M. Res J Pharm Biol Chem Sci 2011; 2(2)

7. Avinash KG, Fast Dissolving Dosage Forms, IJPSI, 2013; 2:14-17.

8.Shweta K, Mayank B, Recent trends in the development of oral dissolving film, Int J PharmTech Res, 2012; 4:725-733.

9. Swamy NGN, Shiva KS, Formulation and evaluation of fast dissolving oral films of palanosetron hydrochloride using HPMCE5, International journal of pharmaceutical and chemical sciences, 2014; 3:145-150.

10. Sri rekha $M$, Shaheda SK, Mahathi $K$, Praveen $P$, PrathimaB, Seetha Devi A, Formulation and evaluation of fastdissolving buccal film containing isradipine soliddispersion, Am J PharmTech Res, 2015; 5:94-107. provides an opportunity for a line extension in a marketplace, for a wide range of drugs (e.g. NSAIDS, antiulcer, antihistamine, Hypnotics \& sedatives, antipsychotics, antiparkinsonism, antiemetic, antimigraine and antidepressants). In future, this system is most acceptable and prescribed due to its quick action i.e. within a minute. Because of increasing patient demand, the popularity of these dosage forms will expand the study in future.

11. Dahiya M, Saha S, Shahiwala A, A review on mouthdissolving films, Curr Drug Deliv, 2009; 6:469-76.

12. Sandeep S, Arun N, Monika HK, Fast Dissolving Films (FDF):Innovative drug delivery system, Pharmacologyonline, 2011; 2:919-928.

13. Naziya K, Raghavendra R NG, Mahipal R, Overview on fast dissolving oral films, Int J Chem Pharm Sci, 2013; 41(9):661-680.

14.Oral mucosal drug delivery: clinical pharmacokinetics and therapeutic applications Zhang, H.; Zhang, J.; Streisand, J.B. Clin. Pharmacokinet, 20

15. Naziya K, Raghavendra R NG, Mahipal R, Overview on fastdissolving oral films, Int J Chem Pharm Sci, 2013; 1:63-75.

16. Mashru RC, Sutariya BC, Parikh PP, Development and evaluation of fast dissolving films of salbutamol sulphate. Drug Dev Ind Pharm. 31; 2005:25-34.

17. Gohel MC, Sharma R, Soniwala MM. Development of taste masked film of Valdecoxib for oral use. Indian Journal of Pharmaceutical Sciences. 2007; 69:318-320.

18. Koland M, Charyulu N, Fast dissolving sublingual films of ondansetron hydrochloride: Effect of addivites on in vitro drug release and mucousal permeation. Journal of Young Pharm. 2010; 2:216-221.

19. Singh S, Gangwar S, Formulation and evaluation of rapidly disintegrating film of levocetrizine hydrochloride. Der Pharmacia Lettre. 2010; 2:434-439.

20. Kulkarni N, Kumar LD, Sorg A, Fast dissolving orally consumable films containing an antitussive and a mucosa coating agent. U.S. Patent 2003, 206942.

21. Juliano C, Cossu M, Preparation, In Vitro Characterization and Preliminary In Vivo Evaluation of Buccal Polymeric Films 
Containing Chlorhexidine. AAPS PharmSciTech. 2008; 9:11531159.

22. Fast Dissolving Oral Films Technology: A Recent Trend For An Innovative Oral Drug Delivery System Deepak Sharma, Daljit Kaur, Shivani Verma, Davinder Singh, Mandeep Singh, Gurmeet Singh, Rajeev Garg, International Journal of Drug Delivery 2015; 7:60-75.

23. Fast dissolving drug delivery system: a review, Arunachalam, A., M. Karthikeyan, S. Ashutoshkumar and K. Kishore,. Journal of Global Trends in Pharmaceutical Sciences, 2010; 1(1):92-110.

24. Upendra CG, Sunil S K, Yuvraj GJ, Praveen DC, Investigation of different polymers, plasticizers and superdisintegrating agents alone and in combination for use in the formulation of fast dissolving oral films, Int J PharmTech Res, 2013; 5:1465-1472.

25. Vishwakarma DK, Tripathi AK, Yogesh P, Maddheshiya B, Review article on mouth dissolving film, Journal of Global Pharma Technology, 2011; 3:1-8.

26. Gavaskar B, Vijayakumar S, Sharma G Rao YM, Overview on fast dissolving films, International Journal of Pharmacy and Pharmaceutical Sciences, 2010; 2:9-33.

27. Kalyan S, Bansal M, Recent trends in the development of oral dissolving films, International Journal of Pharm Tech Research, 42012; 4:725-733.

28. Parul S, Anoop K, Pankaj S, Sharad V, Fast disintegrating oral films: a recent trend of drug delivery, Int J Drug Dev \& Res, 4, 2012; 4:80-94.

29. Fast Dissolving Oral Films: A Review Naga Sowjanya Juluru International Journal Of Advances In Pharmacy, Biology And Chemistry, 2003; 2(1).

30. Handbook of Pharmaceutical Excipients. Wale. A and Weller. P J., 2nd edition, 1994; 24(27):352,448.

31. An Overview of Fast Dissolving Oral Films Chonkar Ankita D., Bhagawati S. T., Udupa N.* Asian J. Pharm. Tech. 2015; 5(3):129137.

32. Development of ebiana, a natural, non-caloric sweetener, Prakash.G.E, DuBois.J.F, Clos.K.L, Wilkens and Fosdick. L.E., Food Chem. Toxicol. 2008; 46:S75-S82.

33. Development of innovative orally fast disintegrating film dosage forms: a review. B.P. Panda, N. S. Dey and M.E.B Rao. International Journal of Pharmaceutical Sciences and Nanotechnology. 2012; 5(2).

34. Oral strip technology: Overview and future potential. Dixit RP, Puthli SP, Journal of Controlled Release.2009; 139:94-107.

35. Technical Brief 2010. Vol 3 Particle Sciences Drug Development Service.

36. Hypromellose, Ethylcellulose and Polyethylene oxide used in hot melt extrusion. Coppens, K.A., M.J. Hall, S.A. Mitchell and M.D. Read, 2005. Pharmaceutical Technol., pp: 1-6.
37. A Short Review on "A Novel Approach in Oral Fast Dissolving Drug Delivery System and Their Patents" M.D. Nehal Siddiqui, Garima Garg and Pramod Kumar Sharma. Advances in Biological Research 2011; 5(6):291-303.

38. Nehal S, Garima G, Pramod K S, A short review on "a novel approach in oral fast dissolving drug delivery system and their patents", Advan Biol Res, 2011; 5:291-303.

39. Pandya K, Patel KR, Patel MR, Patel NM, Fast dissolving films: a novel approach to oral drug delivery, Asian Journal of Pharmaceutical Science \& Technology, 2013; 3:25-31.

40 . Naga Sowjanya Juluru. Fast dissolving oral films: a review. IJAPBC, 2013; 2(1):108-112.

41. Repka MA, Prodduthuri S, Stodghill S.P. Production andcharacterization of hot-melt extruded films containingclotrimazole. Drug Dev Ind Pharm, 2003; 29:757-765.

42. Pallavi C, Patil, Shrivastava SK, Vaidehi S, Ashwini P, Oral fast dissolving drug delivery system: a modern approach for patient compliance, International Journal of Drug Regulatory Affairs, 2014; 2:49-60.

43. Panda BP, Dey NS, Rao MEB, Development of innovative orally fast disintegrating film dosage forms: a review, Int J Pharm Sci Nanotech, 2012; 5:1666-1674

44. Gowri R, Narayanan N, Revathy S, Prabhavathy P, PreethyMG, Rekha G. Melt in mouth films-an effective alternative drug delivery system, 2014, 2666-2680.

45. Rajini B, Pravin P, Sushil K, Sandeep A, Orally dissolvingstrips a new approach to oral drug delivery system, Int J Pharm Investing, 2013; 3:67-68.

46. Han Jung H, Floros John, Casting antimicrobial packaging films and measuring their physical properties and antimicrobial activity. Journal of Plastic Film and Sheeting, 1997; 13:287-297

47. Jutaporn Chana-Thaworn, Suphitchaya C, Thawien W,Properties and antimicrobial activity of edible film incorporated with kaim wood extract, LWT - Food Science and Technology. 2011; 44:284-292.

48. D. Archana J, Vijaya V, Dr. Uma MR, Formulation and evaluation of oral thin films containing saxagliptin, IJJIPSR, 2014; 2:26692690

49. Ankita K, Dr. Pramod KS, Dr. Nayyar P, Fast dissolving oral film: a novel and innovative drug delivery system, IJPSR, 2014; 5:92-95.

50. Sumedha B, Mayank B, Gopal G, Formulation and evaluation of fast dissolving film of an antihypertensive drug, IJPCBS, 2013; 3:1097-1108.

51. Pardeep KJ, Sachin S, Rajni B, Fast dissolving oral films: novel way for oral drug delivery, International Journal of Universal Pharmacy and Bio Sciences, 2014; 3:6-29. 